\title{
School of Ants goes to college: integrating citizen science into the general education classroom increases engagement with science
}

\section{Tyler Vitone, Kathryn A. Stofer, M. Sedonia Steininger, Jiri Hulcr, Robert Dunn and Andrea Lucky}

\begin{abstract}
Citizen science has proven useful in advancing scientific research, but participant learning outcomes are not often assessed. This case study describes the implementation and tailoring of an in-depth assessment of the educational impact of two citizen science projects in an undergraduate, general education course. Mixed-methods assessment of citizen science within a college classroom demonstrates that public participation in scientific research can positively alter attitudes towards science. The timing and type of assessments yielded significantly different results and qualitative assessment provided depth and context. However, disentangling the impact of the course from participation in the projects is the biggest challenge.
\end{abstract}

Keywords Citizen science, Public engagement with science and technology, Science education

Citizen science, also known as public participation in scientific research (PPSR), engages millions of individuals around the world [Bonney et al., 2014]. Many of these endeavors share the paired goals of advancing science through discovery and increasing scientific literacy by involving the public in science. While much attention has been paid to assessing and enhancing the scientific validity of these projects [e.g. Lucky et al., 2014; Bonter and Cooper, 2012], the educational outcomes of participation in citizen science projects have received less scrutiny. Many projects evaluate participant enjoyment, but few projects explicitly test participant learning or changes in attitudes toward science, especially over time [Conrad and Hilchey, 2011; Dickinson et al., 2012]. Investigating these effects of citizen science projects is important in defining their true broader impacts and utility.

Members of the public have gathered data and performed scientific experiments since long before the professionalization of science. Modern-day citizen science was originally conceived to help researchers gather data across larger geographic and time scales and in greater amounts than was possible with a traditional research group [Miller-Rushing, Primack and Bonney, 2012]. Today, PPSR projects cover a broad range of science topics, and vary greatly in the level of participation and amount of time required [Bonney et al., 2009]. 
Content learning as well as non-science outcomes can be the primary goals of citizen science programs, but more commonly these are treated as complementary to scientific research goals such as investigation and conservation [Wiggins and Crowston, 2011]. Educational and affective participant impacts are often assessed in projects deployed in an empowerment or activist framework, where participation involves answering specific (usually community-motivated) scientific questions [Conrad and Hilchey, 2011]. In contrast, projects motivated by basic science may focus on scientific outcomes such as the production of scientifically rigorous citizen-collected data, with less attention paid to the personal value to participants [Shirk et al., 2012].

One explanation for this lack of consideration of participant outcomes is the high level of knowledge of participants in projects that build on pre-existing interests such as hobby activities (e.g. bird watching) [e.g. Corin et al., 2015]. Research studies have shown that would-be participants who lack pre-existing interest in the topic or external motivation to participate are far less likely to follow through and contribute to a citizen science project [Sauermann and Franzoni, 2015].

Other projects that target specific audiences, such as museum visitors or residents of particular geographic areas of interest (for example, urban areas or wetlands) face the challenge of assessing experience in a self-selecting audience comprised of participants with pre-existing exposure to and interest in science, at least in adult programs [Egger, 2007]. This bias in participation has prompted calls for programs to focus on engaging non-traditional participant groups [Haywood and Besley, 2014; Pandya, 2012], including non-science-attentive audiences. This, in turn, has highlighted a need to assess the educational and participant outcomes of citizen science participation. Currently, many citizen science projects do not explicitly ask, and therefore cannot answer, the questions: What do participants learn or otherwise gain from participation? This study outlines our approach to answering these questions in a non-traditional setting, the college classroom.

\section{Educational settings}

Citizen science projects are often incorporated into pre-collegiate and informal science education curricula, such as camps and after-school programs. Less commonly, they have been integrated into undergraduate coursework. At present, the college classroom is an under-utilized venue for assessing citizen science participation with non-science attentive audiences. Most colleges and universities require students to complete general education courses in fields outside their area of study. As such, general-education science courses are populated by students with a diversity of attitudes towards and limited experiences with science.

The principal advantage of assessing citizen science outcomes in a university setting is the opportunity to assess educational outcomes over longer time spans and with larger cohorts than is common with individual public participants. Participants drawn from university-level general education science courses for non-science majors can serve as appropriate proxies for the general public in terms of background knowledge about science topics and experience participating in scientific studies. While university students are often considered more highly educated than the general public, these general-education classes target students in the first and second year of college, at an early stage of professional development. 
Projects that have embedded citizen science in the classroom cite the effectiveness of active learning [Freeman et al., 2014; Coleman and Mitchell, 2014; Powell and Harmon, 2014], collaborative rather than one-on-one models [Frantz, Carruth and Goode, 2014] and incorporation of open- and inquiry-based approaches to learning [Powell and Harmon, 2014]. As such, incorporating citizen science into the general education undergraduate classroom is a promising way to provide authentic research experiences for a diverse range of students with minimal resource demands.

The benefits of experiencing authentic scientific research in an undergraduate setting include helping to stimulate and maintain interest in science and scientific research [Yaffe, Bender and Sechrest, 2014; Gasper and Gardner, 2013; Jacob, 2012; Weaver, Russell and Wink, 2008] as well as increasing self-efficacy and reducing science anxiety [Frantz, Carruth and Goode, 2014]. These affective dimensions are important in establishing lifelong attitudes towards science, regardless of career path, and are directly related to science interest and persistence [Wright, Jenkins-Guarnieri and Murdock, 2012]. Because some students may not even realize their interest in a scientific career until college [Cannady, Greenwald and Harris, 2014], research experiences provide valuable opportunities in science education at the undergraduate level, particularly in general-education courses. Citizen science thus fits a documented need to include authentic research in undergraduate curricula. As availability of funds, space, and faculty mentors can be limited [Frantz, Carruth and Goode, 2014],

this approach provides an alternative to integrating research into undergraduate experiences and is a potential catalyst for sparking scientific interest.

Although the learning outcomes of citizen science participation have been assessed in the context of several undergraduate programs (e.g. the Citizen Science program at Bard College), these instances have not been course-based. Previous studies have focused on the effect of PPSR on student interdisciplinary thinking [e.g. Bestelmeyer et al., 2015], motivation [Carlsen, Goehring and Kerlin, 2014], and appreciation of specific disciplines [e.g. Blake, Liou-Mark and Lansiquot, 2015]. However, an area that has not been explicitly examined is the potential of citizen science projects deployed in the undergraduate setting to generate interest, trust, or intent to participate in science. This study was motivated by the need to understand the learning outcomes and attitude changes that occur as a result of citizen science participation within an undergraduate course context.

\section{Assessment}

Clearly defined educational goals and rigorous evaluation allow projects to measure whether or not science outreach activities are successfully meeting intended goals [Varner, 2014]. In undergraduate science classes, educational goals often focus on content learning while overlooking attitudes toward science in general or, more specifically, understanding of the nature of science [Egger, 2007]. In contrast, citizen science program evaluations have tended to focus on enjoyment and value rather than content learning or behavioral change [Bonney et al., 2009]. This omission reflects a lack of effective metrics for studying these programs [Bonney et al., 2009] as well as a lack of explicit educational goals [Varner, 2014]. 
Challenges in evaluating citizen science programs include the fact that educational goals for citizen science programs may conflict with engagement goals [Haywood and Besley, 2014]. Further, even programs undertaken with appropriate goals and metrics may be unable to show significant participant changes if the particular educational goals are not explicitly addressed in the program activities [Brossard, Lewenstein and Bonney, 2005; Crall et al., 2013]. In spite of these challenges, such programs show potential for addressing cognitive [e.g. Bonney et al., 2009; Jordan et al., 2011], affective [Crall et al., 2013; Price and Lee, 2013] and behavioral goals [Nerbonne and Nelson, 2004]. Standardization of learning outcomes is becoming more prevalent and can be seen in both cognitive content outcomes and, more recently, behavioral and affective outcomes that can be used to evaluate citizen science programs [Bonney et al., 2009].

\section{Objective}

The focus of this study is to assess the educational outcomes of participant involvement in citizen science. Many PPSR programs now exist as clear examples of successful scientific endeavors that engage public participants. While evaluation of the scientific value of a project is usually integral to the study design, the assessment of educational value for public participants is not. In most cases, educational value is presumed to be high but not explicitly assessed.

Educational assessment of citizen science participation is logistically challenging because of the diversity of participants' backgrounds and their experiences while participating. Many are one-time participants while a subset may be involved in a project repeatedly. The approach we explore in this study is to conduct longer-term assessments on a population of participants that experiences participation more uniformly. We do this by evaluating learning gains in a classroom cohort of participants where citizen science projects have been incorporated into an educational curriculum. This solution provides a fitting context for assessing knowledge and attitudes before and after participation and offers the opportunity to use diverse testing tools, such as discussions among participants. The classroom is not a panacea for citizen science assessment, however, and the primary challenge of working within a formal education setting lies in disentangling the effects of participating in a single activity (the citizen science project) from the influence of the course overall.

In this case study we describe the process of designing quantitative and qualitative assessments of two citizen science projects in a university-level general-education science course and outline what type of insight this assessment provides about students' content learning and attitudes toward science. We also highlight the challenges of evaluating project-based learning outcomes in the classroom context.

There is a clear need to develop standardized tools and provide a framework for understanding the impact of citizen science participation at multiple levels. At present, evaluation of individual case studies can offer valuable insight into the experience of citizen science participants and the influence of participation on content learning and attitudes about science. Case studies provide a mechanism for studying an instance of a program and its participants in-depth [Yin, 2009], often using mixed methods designs [Johnson and Onwuegbuzie, 2004]. 
A case study approach is often used to build up a rich picture of an entity, using different kinds of data collection and gathering the views, perceptions, experiences and/or ideas of diverse individuals relating to the case... it can give the researcher in-depth insights into participants' lived experiences within this particular context" [Hamilton, 2011, p. 1].

This case study chronicles an investigation of the affective and learning outcomes of a citizen science program embedded in a general education course for non-science majors at a large research university. In this case study, we present the quantitative and qualitative assessment tools used and data gathered over five semesters of implementation of the project in the classroom.

\section{The course}

The citizen science activities assessed in this study were embedded in The Insects (ENY 2040), an undergraduate entomology course at the University of Florida. The course fulfills a biology general education requirement and therefore draws a diverse enrollment in terms of students' majors, interest in entomology and interest in and experience with scientific research. Co-authors AL and TV taught this course using the same course structure and content over the period of this study, from 2013-2015.

\section{Citizen science activity}

Each student enrolled in The Insects was assigned to participate in one of two citizen science projects: School of Ants (SoA) www.schoolofants.org or Backyard Bark Beetles (BBB) www.backyardbarkbeetles.org. Participation in the activity was a required assignment within the course ( $5 \%$ of total grade, based on completion). Both projects were discussed in lectures on the related topics of social insects and insect forest pests, respectively. Participation in each project involved collecting insects locally to contribute to mapping and monitoring studies. Both projects follow simple protocols for collecting insects and recording data and require similar time and effort.

The School of Ants project invites participants to collect ants near a home, school or work by placing crumbled cookies on an index card in two types of environments: a paved space (such as a driveway or sidewalk) and a green space (such as a lawn or garden). Almost universally, ants discover crumbs quickly during warm weather. After one hour, the cards, with ants and crumbs, are scooped into a zip-top plastic bag. Participants record data about collection locality and ambient conditions, freeze the ants overnight and then deliver them in person or by mail to the laboratory of AL at the University of Florida. There, ants are identified to species and the collection locality of each is added to an interactive map of the species' known range. Through the project website, participants learn about the identity and basic biology of the ants they collect, as well as about the species other participants have collected.

The Backyard Bark Beetles project provides instructions for participants to make a simple beetle collection trap using a 2-litre bottle baited with ethanol-based hand sanitizer. Participants hang the trap for 24-48 hours, then collect the trapped 
Table 1. A summary of assessment tools used in the course by semester. Tools changed over time to optimize the educational assessment.

\begin{tabular}{|c|c|c|c|c|c|c|}
\hline \multirow{2}{*}{ Assessment tool } & \multicolumn{4}{|c|}{ Semester } & Total Number of students \\
\cline { 2 - 5 } & 1 & 2 & 3 & 4 & \\
\hline Focus Group & $\mathbf{X}$ & & & & 4 \\
\hline Pre- and post tests & $\mathbf{X}$ & $\mathbf{X}$ & $\mathbf{X}$ & $\mathbf{X}$ & 102 \\
\hline Objective questions in assessment & $\mathbf{X}$ & $\mathbf{X}$ & $\mathbf{X}$ & $\mathbf{X}$ & 102 \\
\hline Citizen science written discussion & $\mathbf{X}$ & $\mathbf{X}$ & $\mathbf{X}$ & $\mathbf{X}$ & 102 \\
\hline Attitude questions in pre- and post-tests & & $\mathbf{X}$ & $\mathbf{X}$ & $\mathbf{X}$ & 74 \\
\hline Retrospective pre- and post tests & & & $\mathbf{X}$ & $\mathbf{X}$ & 34 \\
\hline
\end{tabular}

beetles into a zip-top bag and either deliver or send the beetles to the laboratory of AL at the University of Florida. Just as in the School of Ants project, the insects are identified and mapped onto an interactive online map. Collectors learn about the species they have collected as well as other species that occur locally.

Students were assigned by the instructor to complete one of the two projects. First, the class was divided into two groups of similar size and background knowledge about insects. Prior knowledge of entomology was assessed based on student performance on an ungraded, objective, multiple-choice pre-test at the start of the course (Supplement 1). The citizen science projects were then assigned to these two groups at random. Students were given approximately one month to independently complete the assigned activity. This assignment occurred mid-semester, after students had been exposed to the basics of entomology: nomenclature, insect identification and insect evolution.

Over the course of five semesters, several assessments were implemented and iteratively refined in order to evaluate the effects of citizen science project participation (Table 1). Assessments began with a pre-course evaluation at the beginning of the semester, consisting of entomology-based content questions. The same survey was issued at the end of the semester as a post-course evaluation. Subsequent additions to the content-based pre- and post-course survey were to introduce affective and value questions and to expand the post-test to include a retrospective pre-test (see Post-Test subheading), which asked students at the end of semester to recall opinions and perspectives held at the beginning of the semester. Additionally, qualitative, open-ended discussions were incorporated as a method of assessment, first through a focus group and subsequently through online discussions.

\section{Pre-course survey}

A pre-course test assessed students' incoming knowledge about insects and attitudes about science (See Supplement 1). This test included questions directly related to the citizen science project topics (forest insect pests and social insects). In the first semester of evaluation, only content questions were included on this test but in later semesters five subjective questions were included (included in Supplement 1). The subjective questions were included to help tease apart the effect of project participation from the course at large. These questions asked students to rank their opinions/views on their: 1) trust in science, 2) interest in science, 3) 
interest in entomology, 4) interest in participating in scientific activities (i.e. citizen science, research) as one of five increasing ranks (low, low-medium, medium, medium-high, high) and 5) the importance for the general public to be informed about science and technology as one of five increasing ranks (not important, minimally important, somewhat important, very important, extremely important). Of these questions, number 4 most directly assessed students' opinions on the citizen science project.

\section{Post-course survey}

To assess student improvement and opinion changes over the semester, an ungraded post-course survey, identical to the pre-course survey, was presented to students at the end of the course (see pre-course survey in Supplement 1). In later iterations of the course, the post-test structure was modified to include two sets of the same questions, but qualified differently. The first questions asked students to recall their opinions at the beginning of the course, using "Before taking this course..." language. This is known as a retrospective pre-test [Campbell and Stanley, 1963]. The second questions were the traditional "post-test" to collect student opinions at the end of the course - questions with "After taking this course..." language. The final version of this assessment thus included 'pre-course', post-course' and 'retrospective-pre-course-' tests in order to account for difference in perspective from the beginning to the end of the semester. This can account for, for example, students forgetting how they completed the pre-course survey. More interestingly, this can identify shifts in students' perceptions of their own pre-course positions as a result of experience gained over the semester [Sibthorp et al., 2007].

\section{Discussions}

An optional focus group discussion was held during the first semester of assessment to gauge students' perspectives on how participation in a citizen science project affected their learning in the course. The anonymous discussion was led and recorded by trained facilitators from the UF Teaching Resources Center who were not connected to the course. Facilitators compiled student responses so that individual student identities remained anonymous to instructors. Because a limited number of students (4 out of 38) opted to participate despite incentives (free pizza, contribution to educational research), this assessment tool was replaced in subsequent semesters by a graded, written discussion on the topic of citizen science. Grading for this assignment was explicitly based on completion, not content, in order to encourage authentic viewpoints. Students were prompted to address the question "Can Citizens be Effective Scientists?" by the following instructions:

Based on your experience with our citizen science activity, do you think engaging non-scientists is the way to move forward with large-scale science? Or, alternatively, do you think that the benefits of citizen science lie largely in the realm of science education? Offer examples of the following in your commentary:

1. An example of how the field of science itself can benefit from scientific initiatives that involve the public 
2. A long-term benefit for the public involved in these projects

3. List at least TWO challenges that citizen science projects might face

4. As always, make sure to end with a question to keep the discussion moving forward

In order to minimize bias in student discussion responses as a consequence of this being a graded assignment, students were explicitly informed that their discussion grade would be based on completeness, not on content, and that there were no correct answers. Discussion instructions emphasized the expectations of thoughtful opinions, respectful dissent and drawing upon the support of facts. By the time students completed this discussion (the sixth of six during the semester) they were familiar with the grading scheme, in which full points were assigned for a response which, at minimum, answered all prompts. Students were able to read and respond to classmates' responses only after completing their own. While we cannot be certain that students felt completely comfortable answering honestly in a graded discussion, we were encouraged that this was the case for most students based on the length of responses and the appearance of negative responses. Most students answered in approximately 200-300 words (minimum would have required approximately 50 words). In each semester, some students included negative perceptions of citizen science's value for science and/or education, although these constituted the minority of responses.

\section{Consent, confidentiality and data exclusion}

All students taking the course were informed that the class was connected to a study on education and had the option to opt out of having their data included in this study. Study design and consent language were approved by University of Florida's Institutional Review Board (IRB\#2014-U-703). Data from individual students were excluded from analyses based on student choice to opt-out, failure to complete the pre- and/or post-test and failure to complete the assigned citizen science activity. Data for each student were de-identified after the close of each semester (names replaced with numbers; the key controlled by the instructor) before analyses were performed.

\section{Data analysis}

Paired t-tests were performed to test for changes in mean opinion ranks of students among the pre-, retrospective-pre-, and post-course tests. Discussion prompts were analyzed using thematic coding [Auerbach and Silverstein, 2003] to find repeating elements. As we were specifically interested in students' positive and negative reactions to citizen science, we used these as initial expected codes [Miles and Huberman, 1994], but we also remained open to emergent codes [Bogdan and Biklen, 2007]. We also looked specifically at the question of benefits of citizen science to society for examples given in lecture versus student-generated examples.

Student responses were analyzed to determine: 1) what students considered to be a long-term benefit for the public (question 2) and how this differed from what was taught in lecture, 2) what students listed as challenges to projects, 3) whether they 
mentioned if they had ever heard of citizen science before taking this course, 4) whether they stated that would participate in another project and under what circumstances, and 5) whether they listed another citizen science project (or other relevant online source) they came across on their own in response to this discussion.

Results

The final version of the course assessment consisted of 1) a pre-test of content-based and subjective, Likert-type scale questions at the beginning of the semester, 2) online discussion boards specifically addressing the citizen science project participation, and a 3) a post-test of content-based and subjective, Likert-type scale questions at the end of the semester as well as 4) a retrospective pre-test comprised of only subjective questions, issued at the end of the semester.

\section{Content mastery}

Student performance on post-test content questions was not correlated with participation in either of the projects. Both the group assigned to the School of Ants project and the group assigned to the Backyard Bark Beetles project showed increased numbers of correct responses on both questions related to ants and to beetles between pre- and post-tests. Increased content-specific performance, however, was not associated with the specific project assignment (Figure 1).
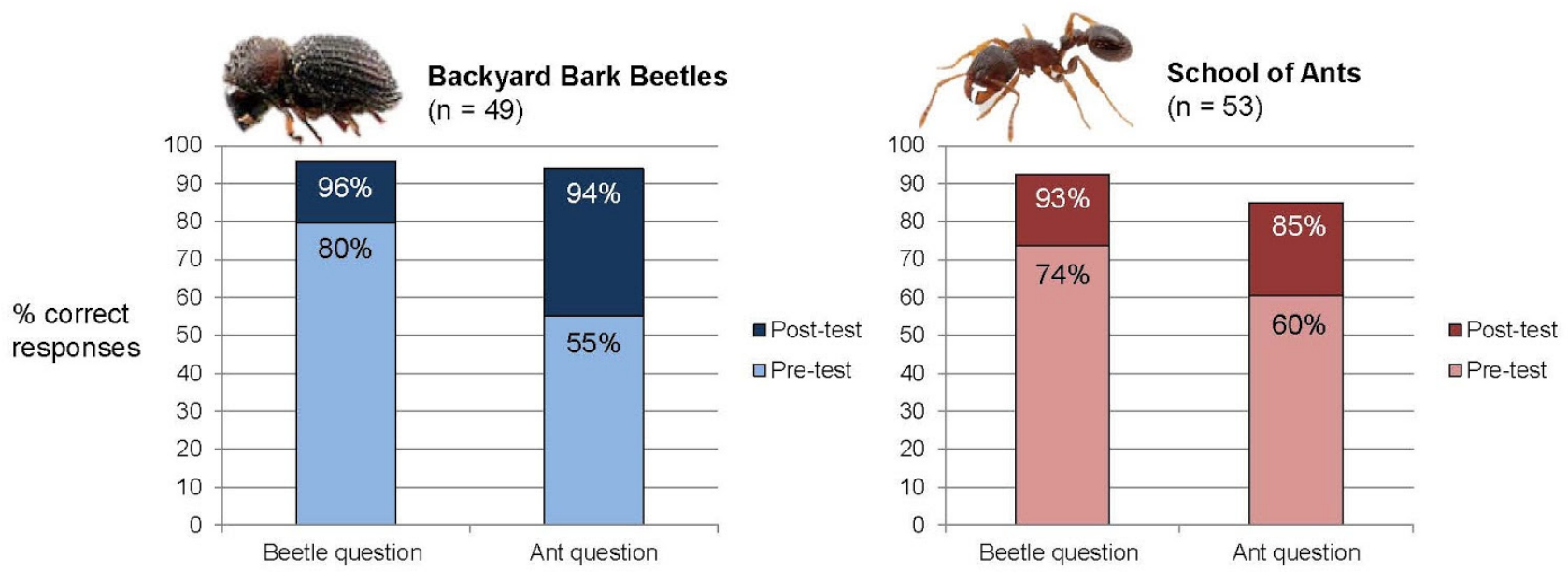

Figure 1. Percentage of correct responses on the ant and beetle specific test questions at the start and end of the course. Projects were assigned to students, and project groups were arranged so that each included students with equivalent pre-course knowledge of entomology. Dark shaded bars show improvement so that the total height of the bar indicates the percentage of students correctly answering the question at the end of the course. Actual percentage correct shown within each bar (Backyard Bark Beetles, $n=49$ students; School of Ants, $n=53$ students). Photos (not to scale) courtesy of Jiri Hulcr (beetle = Hypothenomus sp.; http://www.ambrosiasymbiosis.org/) and Alexander Wild (ant = Tetramorium sp. E; http:/ / www.alexanderwild.com/).

\section{Attitudes about science}

There were significant differences in the mean rank of students' attitudes at different points in the course (Figure 2), suggesting that the timing of the 
assessments significantly affected results. When using paired sample t-tests to compare students' pre-test ranks at the beginning of the course to their ranks in the "After taking this course..." questions, only one attitude change was significant the mean rank in interest in entomology was significantly higher after taking the course $(\mathrm{p}=0.003)$. However, when comparing the retrospective pre-test ("Before taking this course...") to the post-test, mean rank change increased in all category questions (with $\mathrm{p} \leq 0.03$ ). Analyses also revealed pre- and retrospective pre-test ranks differed significantly for three of the attitude questions. Thus, students ranked their opinions differently in the retrospective-pre-test than they did at the beginning of the course.

The largest positive attitude changes were observed in students' interest in 1) entomology and 2) participating in science (i.e. citizen science projects). These were also the questions with the lowest mean ranks in the pre-tests. Students ranked the importance of a scientifically literate public highest in all tests, regardless of the timing of test administration. Comparisons of pre- post- and retrospective pre- tests include students from only two semesters of the course (when the retrospective pre-test was introduced). However, these data are consistent with the data from pre- and post-tests from all semesters of the course.

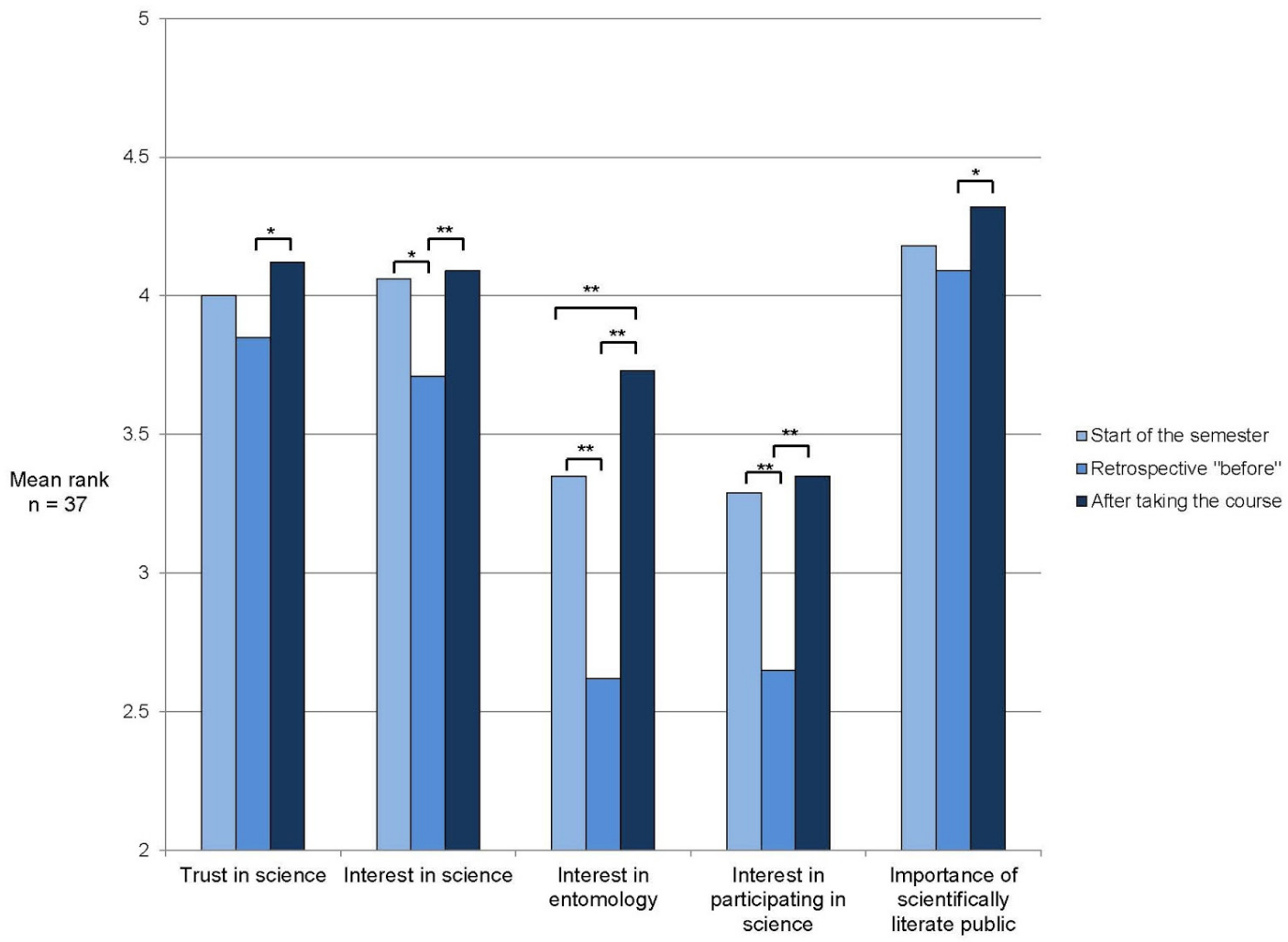

Figure 2. Mean ranking of students' attitude towards five subjective questions about science. A rank of 5 was the most positive score (high interest/extremely important) while a rank of 1 was the most negative score (low interest/not important). Students were assessed at the start of the semester and after taking the course when they also answered a retrospective "before taking this course..." question. Brackets with a single asterisk $\left(^{*}\right)$ indicate p-values of $<0.05$, double asterisks $\left.{ }^{(* *}\right)$ indicates $\mathrm{p}<0.01$. 


\section{Student discussions}

Student discussion responses about citizen science participation encompassed the full spectrum, from positive to negative experiences. In discussing the benefits of citizen science to society, the majority of student answers focused on education, awareness, or understanding ( $69 \%$ and $55 \%$ of responses, respectively). These can be considered elements of science literacy, which was explicitly mentioned as a benefit in the lecture portion of the course. Other benefits explicitly mentioned in class, interest in science and trust in science, were included in only a handful of student responses (12\% and $22 \%$, respectively). Students most commonly cited accuracy and motivating the public as challenges to conducting PPSR projects, with one or both mentioned in nearly all student responses. Other challenges, such as time, coordination, and not collecting the right target species were only mentioned once each.

Unprompted comments that were included regularly in student discussions related to knowledge about citizen science. In one semester, over $25 \%$ of the class referenced in their discussion post that they were unaware of citizen science projects prior to taking the course. In the same semester, over $30 \%$ of students (8 in total) included an unprompted reference to a different PPSR project than those used in the course. In another semester, over 30\% of the class indicated that they would participate in another PPSR project if the subject matter interested them.

\section{Positive perceptions}

Positive student responses included perceptions that participation in the projects achieved important results with little effort on the part of the participant. "Although it was something small, ... with the inclusion of everyone else's submission along with mine, a difference is definitely made," noted one participant. Students also saw the value of citizen science in diverse fields, as one said, "[t]here is so much to be discovered by amateur horticulturists, star-gazers, chemists, engineers, entomologists, geologists, biologists, etc., that surely everyone can find something that interests them."

Some students also expressed surprise that they had not heard of PPSR before the class, such as one who said, "[m]y major is nowhere near related to the sciences, but I was still surprised to having never heard of it being discussed by friends who are [science majors]." They also expressed that they learned quite a bit. One noted, "I wasn't originally familiar with Citizen Science, but I would probably do it again if given the opportunity just because of all that I learned from it."

Finally, students reported that the projects were interesting and expressed dismay that more people were not involved or interested, "I think that it's kind of sad that there is a lack of interest in projects like the ones we got to participate in because it wasn't difficult or extremely time consuming." Another said, "I will definitely consider doing another citizen science project and possibly telling my friends and family to join me! I think it's a great hands-on way to learn about community." 


\section{Qualified perceptions}

Some students felt that citizen science had value to the scientific community, but with limits, and revealingly, voiced doubts about their own expertise, saying, "[w]ith more simple assignments like collecting insects I think I can be of great assistance and perform as the scientists would hope. However, with a more advanced level of science requiring a deeper understanding to participate (say something in organic chemistry), I don't think I can accomplish the tasks at a level the scientists need for accurate/relevant data." A lack of expertise, some suggested, could actually potentially backfire for getting the public engaged in science, as if a participant "make[s] one mistake they will feel as if they should not start over and they may even feel embarrassed at the fact that they messed up their part of the findings."

Other qualified responses pointed out ways that the projects were helpful in making the experience valuable, suggesting "the tasks are broken down into approachable steps that are not overly burdensome, and that people can see how they are a part of something and how their work helps fit into the bigger picture. With the projects we did, it was not too difficult, and there is also feedback with species identification."

\section{Negative perceptions}

Negative comments from students showed they had several frustrations with the process of the activity, many of which related to the time and effort to complete the activity. "I would honestly not participate in this particular citizen science project if it was not for a grade. It took lots of time to gather materials and monitor them. There are also unforeseen circumstances that can go wrong, which can leave a person unmotivated to keep going for this type of project. I was in the "School of Ants" and I remember ducks in the area trying to eat the cookies left out for the ants. I ended up having to relocate. It wasn't terrible, but if I had a choice to do it again, I probably would not."

Other student comments revealed questions about the need for citizen science. One student questioned whether any individual's participation, especially as a volunteer rather than someone identified by the scientific team, was necessary, saying "[i]f there are other people who will do the project, then why would I? I would be much more inclined to do this if I was asked as an individual to participate rather than volunteer to do it on my own." Another student did not feel that citizen science did not appeal to values held by the general public, "[m]uch like myself, society has a poor mindset of not engaging in things which does not appear to be interesting or beneficiary, and at face value, citizen science doesn't adhere to either factor. So, citizen science will not work on a larger scale."

Some students' negative comments focused more specifically about the value of citizen science in the undergraduate classroom, or to adult audiences. "When I was doing the ants project my younger nephews were excited to help and wanted to do other projects, personally I was not so excited to do the project because I have other things going on, which is how I feel other adults would be too. When it is geared towards a younger population I think it could be positive and make children want 
to learn more about science." A subset of students expressed concern about the external motivation of a grade detrimentally affecting the quality of data collected, "[m]ost people who become involved in these projects is out of interest and they are careful when conducting their research. However, when it is assigned for a class such as this one, I feel like the chances of error are a lot higher because they are being forced to do it and do not care whether their procedures have errors."

\section{Conclusions}

This study demonstrated that undergraduate classrooms can provide an appropriate context for assessing the educational outcomes of PPSR, particularly for affective including both learning and affective outcomes. The benefits of working in a course setting include the ability to use diverse tools to survey background knowledge and assess post-participation learning gains over longer periods of time than typically possible with public volunteers. Classrooms can also offer a more diverse cohort of participants in terms of background knowledge and interests than the typical audience of citizen science volunteers, who are often driven by their own hobbies and interests. When assessment tools are appropriately tailored to classroom context, they can effectively capture both knowledge gain and attitude shifts. One important challenge to assessing PPSR in formal educational settings, however, is the difficulty in separating the effects of participating in a single project from the overall impact of the course.

\section{Assessment methods}

This case study outlined the evolution of a mixed-methods assessment of undergraduate student learning through citizen science participation. The process resulted in a more nuanced understanding of what students learn, but also highlighted the importance of how impacts are assessed, over the short- and longterm. Importantly, participation clearly affected attitudes about science. This result is a direct consequence of using an approach that incorporated qualitative and quantitative assessment tools, including both subjective and content-based questions in quantitative assessments as well as structured discussions. Using mixed-methods assessment allowed us to track changes in student attitude and learning over the course of the semester and also to dig deeper into the reasoning behind these shifts. Qualitative discussion questions revealed important insights about student motivation that were not captured in pre- and post-test quantitative comparisons.

In contrast to expectations, participation was not found to affect content knowledge-based student performance. Although our assessments effectively captured attitude shifts as a result of participation in citizen science projects, the quantitative approach used here may not have been powerful enough to detect content-based learning gains. This result contrasts with the findings of Brossard et al. (2005), who reported that participants of a citizen science project gained content knowledge but did not change their opinions of science. A major distinction between these two studies and a possible explanation for the discrepancy is that in the present study the undergraduate course represented a different population sample and context as compared to an audience composed of volunteers. In particular, classroom students participated in citizen science based on course enrollment rather than as volunteers pursuing a personal interest. 
Future studies are likely to benefit from inclusion of more extensive content-related quantitative assessments than were used here. Despite the fact that our results did not detect content-based learning gains associated with participation in citizen science projects, we expect that this reflects limitations of the quantitative component of the study. Current literature suggests that participation in citizen science projects can significantly aid content knowledge acquisition and retention, and assessments should aim to test this explicitly.

One challenge to studying educational outcomes in the context of a college course is the difficulty of disentangling the impact of citizen science project participation from the effect of the science course in general. Student performance increases from the pre- to the post-test are certainly due in part to learning gains from lectures and not exclusively as a result of active participation in citizen science. On the other hand, students' attitude changes can be directly tied to personal experience with PPSR through surveys that references citizen science participation. It remains unclear how much learning gains can be attributed directly to citizen science participation. Ideally, researchers designing citizen science assessments in a classroom context should attempt to delineate content between the citizen science project and the rest of the course in order to assess effects of citizen science project participation separately from course material more generally. Specifically, we recommend that in courses where there is significant overlap in the topic of the course and the project (i.e. entomology, as in this study), the focus of assessment should be on attitudes about the mode of participation (i.e. scientific research). Conversely, where the type of participation in the course and project are similar (i.e. in a research methods course) the focus should be on disciplinary content learning.

\section{Timing of testing}

The point during the semester at which students were surveyed about their attitudes toward science mattered. Students reported pre-course attitudes very differently when they were asked at the beginning of the course (pre-test scores were neutral) versus when they were asked at the end of the course to remember their attitudes before the course began (retrospective pre-test scores were more negative). This difference, known as response-shift bias, is expected in situations where test-takers lack self-knowledge before gaining experience in a new field (i.e. entomology for non-science students), and is less pronounced in areas where test-takers already have topical expertise (i.e. importance of science literacy). Studies examining this pattern in survey responses have consistently found that retrospective pre-tests provide higher correlations with objective and performance measures than pre-program pre-tests [Sibthorp et al., 2007, and references therein].

A possible alternative explanation for this pattern is that students simply may not remember their responses at the start of the semester, although this would be unlikely to result in the significant decrease in perceived knowledge seen here. Another possible explanation consistent with response-shift bias is that the lower scores seen in the retrospective pre-test serves to emphasize the contrast to the post-test. That is, a student who has undergone an attitude shift over the course of the semester can indicate this by selecting a higher score at the end of the semester and by selecting a lower score describing pre-course attitudes [Campbell and Stanley, 1963]. Because participants' motivation and interest in citizen science 
projects is dynamic throughout the course of participation [Rotman et al., 2012], timing of testing should be taken into account when designing assessments.

\section{Student discussions}

Student discussions provided qualitative insights into the use of citizen science projects in the undergraduate classroom that were not captured with quantitative pre- and post-test comparisons. The student responses included positive and negative perceptions, mirroring patterns from the quantitative data and providing data triangulation. These discussions were particularly insightful regarding ways to better integrate citizen science into the classroom, motivations behind students' performance, and concerns about data quality.

Positive comments underscored the power of authentic experiences to build interest and motivate learning. Many students stated that they would participate in another project and/or gave information about other PPSR projects. This could be an indication that, without being specifically prompted by the instructors, they were open to participating in science and searched for projects that may interest them. The comments also indicated that citizen science was a new concept to many students, pointing to a role for undergraduate classes in increasing awareness about citizen science in general.

The negative comments also hint at larger views about society and science that may not actually be reflective of public perceptions, perhaps a form of situational stereotype threat [Steele, 1997] faced by "non-scientists" asked to perform as scientists, or a manifestation of science anxiety [Alvaro1978; Mallow, 2006]. Students may perceive a level of disinterest about science, or that projects such as these are more suited for children, but the American adult public actually reports high levels of interest in science [e.g. Miller, 2010]. Students who were frustrated by the process of science and "unforeseen circumstances" (e.g. a duck eating the samples) may not realize this is actually quite common in science practice. For general education science classes, explicit discussion about the relevance of science to society and the process of science (warts and all) is likely to benefit the goals of PPSR and to help students to value, understand, participate in and/or pursue careers in science.

In this study, analyses of discussion responses also revealed concrete suggestions for better aligning projects and assessments with student experience and improving outcomes. When asked to list benefits of citizen science, students most commonly cited environmental awareness, yet this topic was not included in attitude or content surveys, nor was it addressed explicitly in the course or projects. Another area of dissonance was student lack of understanding of the practical concerns of scientists who design and run citizen science projects. Students rarely cited considerations such as time, funding, and collecting relevant data, rather, they viewed the primary challenges of citizen science projects as data accuracy and motivation. Many citizen science projects, including the two used in this study, have demonstrated the accuracy and utility of public collections [Lucky et al., 2014; Steininger et al., 2015], but all such programs face logistical and funding hurdles. It is likely that students will feel more confident in their own abilities and prepared to participate in the process if they have a more accurate understanding of the process of creating and running PPSR projects. 
In summary, the power of engaging public and educational audiences in authentic research is clear, as it provides understanding and appreciation of the process of science as well as longer-term motivation for sustained science learning [Bell et al., 2009; National Research Council, 2005]. Incorporating citizen science in college classes is one path toward involving authentic research in the undergraduate classroom that can benefit both science and participants. As such, assessment of educational outcomes should be a priority for citizen science programs, particularly assessments that explicitly consider learning outcomes, both those based on content knowledge as well as those based on attitudes about science.

Acknowledgments We thank all the participants in the School of Ants and Backyard Bark Beetles projects for their engagement. We are grateful to the UF Teaching Resources Center for facilitating focus group discussions. Support for this research was provided by NSF DEB \#1256968 and a Roche Teaching Fellowship to AL from the University of Florida's College of Agriculture and Life Sciences. IRB approval was obtained for this research under protocol IRB02\#2014-U-703. 


\section{ENY 2040 Pre-post ENTOMOLOGY assessment}

1) How many species of insects do you think can be found in and around your home?

$0-100$

$1001-10,000$

$10,001-100,000$

$100,001-1,000,000$

I don't know

2) Exotic species that become pests when introduced into

a new environment are considered:

Native

Invasive

Health hazards

All of the above

I don't know

3) Insects are a

Kingdom

Class

Family

Species

I don't know

4) Insects communicate through chemicals known as:

Musk

Trails

Pheromones

Hydrocarbons

I don't know

5) Insects, spiders, scorpions, mites, crabs and shrimp are

all examples of

Arthropods

Annelids

Crustaceans

Vertebrates

I don't know

6) Insect that are considered fully 'Social' must have

which of the following characteristics?

Fertile queens and sterile workers

Elaborate mating displays

Large territories

A painful defensive sting

I don't know

7) The hard outer covering of an insect is known as the

Endoskeleton

Exoskeleton

Hemiskeleton

Nanoskeleton

I don't know

8) Which group of animals is the most diverse on earth? Birds
Fish

Spiders

Insects

I don't know

9) Which group of insects is the most diverse on earth? Beetles

Ants

Butterflies

Moths

I don't know

10) Which insects are common pests of household pets? Lice

Fleas

Botflies

Rat-tailed maggots

I don't know

11) Which insects are NOT important decomposers in

forest ecosystems?

Termites

Assassin Bugs

Beetles

Cockroaches

I don't know

12) Which of the following insects are the most successful eusocial animals on earth?

Butterflies and Moths

Ants and Termites

Spiders and Mites

Beetles

I don't know

13) Which species of insect is the single most important for pollination of crops worldwide?

Honeybee

Bumblebee

Cabbage butterfly

Potato beetle

I don't know

14) Which term describes the transition from pupa to

adult?

Aposematism

Apterygota

Entomophagy

Metamorphosis

I don't know

15) Which type of insect is a destructive forest pest?

Ladybug

Silverfish

Ant

Bark Beetle

I don't know 


\section{ENY 2040 Pre-course Science Attitude Assessment}

1) I would rate my level of trust in science as:

Low

Low-medium

Medium

Medium-high

High

2) I would rate my level of interest in science as:

Low

Low-medium

Medium

Medium-high

High

3) I would rate my level of interest in entomology as:

Low

Low-medium

Medium

Medium-high

High

4) I would rate my level of interest in participating in scientific activities (i.e. citizen science, research, etc.) as: Low

Low-medium

Medium

Medium-high

High

5) I think it is for the general public to be informed about science and technology:

Not important

Minimally important

Somewhat important

Very Important

Extremely important

\section{ENY 2040 Post-course Science Attitude Assessment}

1a) I would rate my level of trust in science after taking this course as: Low

Low-medium

Medium

Medium-high

High

1b) I would rate my level of trust in science before taking this course as:

Low-medium

Medium

Medium-high

High

2a) I would rate my level of interest in science after taking this course as:

Low-medium

Medium

Medium-high

High

2b) I would rate my level of interest in science before taking this course as:

Low

Low-medium

Medium

Medium-high

High

3a) I would rate my level of interest in entomology after taking this course as:

Low

Low-medium

Medium

Medium-high

High

3b) I would rate my level of interest in entomology before taking this course as:

Low

Low-medium

Medium

Medium-high

High 
3a) I would rate my level of interest in entomology after taking this course as:

Low-medium

Medium

Medium-high

High

3b) I would rate my level of interest in entomology before taking this course as:

Low

Low-medium

Medium

Medium-high

High

4a) I would rate my level of interest in participating in scientific activities (i.e. citizen science, research, etc.) after taking this course as:

Low-medium

Medium

Medium-high

High

4b) I would rate my level of interest in participating in scientific activities (i.e. citizen science, research, etc.) before taking this course as:

Low

Low-medium

Medium

Medium-high

High

5a) After taking this course I think it is Not important for the general public to be informed about science and technology:

Minimally important

Somewhat important

Very Important

Extremely important

5b) Before taking this course I thought it was

technology:

Not important

Minimally important

Somewhat important

Very Important

Extremely important

\section{ENY2040 Discussion Question}

Question: Can Citizens be Effective Scientists?

Instructions: Based on your experience with our citizen science activity, do you think engaging non-scientists is the way to move forward with large-scale science? Or, alternatively, do you think that the benefits of Citizen Science lie largely in the realm of science education?

Offer examples of the following in your commentary:

1) An example of how the field of science itself can benefit from scientific initiatives that involve the public

2) A long term benefit for the public involved in these projects

3) List at least TWO challenges that Citizen Science projects might face

4) As always, make sure to end with a question to keep the discussion moving forward

Looking forward to your contributions to the discussion

Dr. Lucky 
Alvaro, R. A. (1979). 'The effectiveness of a science therapy program upon science anxious undergraduates'. Retrieved from ProQuest Dissertations \& Theses Full Text. (302916772). PhD thesis. Chicago, IL, U.S.A.: Loyola University of Chicago.

Auerbach, C. and Silverstein, L. B. (2003). Qualitative Data: An Introduction to Coding and Analysis. New York, NY, U.S.A.: NYU Press.

Bard College (n.d.). Citizen Science. URL: citizenscience . bard .ed.

Bell, P., Lewenstein, B., Shouse, A. W. and Feder, M. A., eds. (2009). Learning Science in Informal Environments: People, Places, and Pursuits. Washington, D.C., U.S.A.: National Academies Press. URL: http://www.nap.edu/catalog/12190.

Bestelmeyer, S. V., Elser, M. M., Spellman, K. V., Sparrow, E. B., Haan-Amato, S. S. and Keener, A. (2015). 'Collaboration, interdisciplinary thinking, and communication: new approaches to K-12 ecology education'. Frontiers in Ecology and the Environment 13 (1), pp. 37-43. DOI: 10.1890/140130.

Blake, R. A., Liou-Mark, J. and Lansiquot, R. D. (2015). 'Promoting the Geosciences Among Grades 8-12 Minority Students in the Urban Coastal Environment of New York City'. Journal of Geoscience Education 63 (1), pp. 29-40. DOI: 10.5408/13-101.1.

Bogdan, R. and Biklen, S. K. (2007). Qualitative Research for Education: An Introduction to Theories and Methods. 5th ed. Boston, MA, U.S.A.: Pearson/Allyn and Bacon.

Bonney, R., Ballard, H., Jordan, R., McCallie, E., Phillips, T., Shirk, J. and Wilderman, C. C. (2009). Public Participation in Scientific Research: Defining the Field and Assessing Its Potential for Informal Science Education. A CAISE Inquiry Group Report. URL: http://eric.ed.gov/?id=ED519688.

Bonney, R., Shirk, J. L., Phillips, T. B., Wiggins, A., Ballard, H. L., Miller-Rushing, A. J. and Parrish, J. K. (2014). 'Next Steps for Citizen Science'. Science 343 (6178), pp. 1436-1437. DOI: 10.1126/science. 1251554.

Bonter, D. N. and Cooper, C. B. (2012). 'Data validation in citizen science: a case study from Project FeederWatch'. Frontiers in Ecology and the Environment 10 (6), pp. 305-307. DOI: 10.1890/110273.

Brossard, D., Lewenstein, B. and Bonney, R. (2005). 'Scientific knowledge and attitude change: The impact of a citizen science project'. International Journal of Science Education 27 (9), pp. 1099-1121. DOI: 10.1080/09500690500069483.

Campbell, D. T. and Stanley, J. (1963). Experimental and Quasi-Experimental Designs for Research. Belmont, CA, U.S.A.: Wadsworth Cengage Learning.

Cannady, M. A., Greenwald, E. and Harris, K. N. (2014). 'Problematizing the STEM Pipeline Metaphor: Is the STEM Pipeline Metaphor Serving Our Students and the STEM Workforce?' Science Education 98 (3), pp. 443-460. DOI: 10.1002/sce.21108.

Carlsen, W. S., Goehring, L. and Kerlin, S. C. (2014). 'From Local to EXtreme Environments (FLEXE): Connecting Students and Scientists in Online Forums'. In: Geoscience Research and Outreach. Ed. by V. C. H. Tong. Innovations in Science Education and Technology. Springer Netherlands, pp. 81-89. DOI: 10.1007/978-94-007-6943-4_6.

Coleman, J. S. M. and Mitchell, M. 'Active Learning in the Atmospheric Science Classroom and Beyond Through High-Altitude Ballooning'. Journal of College Science Teaching 44 (2). URL: http://digital.nsta.org/article/Active+Learn ing+in+the+Atmospheric+Science+Classroom+and+Beyond+Through+High-Alt itude+Ballooning/1839234/229574/article.html. 
Conrad, C. C. and Hilchey, K. G. (2011). 'A review of citizen science and community-based environmental monitoring: issues and opportunities'. Environmental Monitoring and Assessment 176 (1), pp. 273-291. DOI: 10.1007/s10661-010-1582-5.

Corin, E. N., Jones, M. G., Andre, T., Childers, G. and Hite, R. (2015). Where do they Fit? Astronomy and Birding Hobbyists in the STEM Learning Ecosystem. Poster presented at the American Educational Research Association annual meeting, Chicago, IL, U.S.A., 11th April 2015.

Crall, A. W., Jordan, R., Holfelder, K., Newman, G. J., Graham, J. and Waller, D. M. (2013). 'The impacts of an invasive species citizen science training program on participant attitudes, behavior, and science literacy'. Public Understanding of Science 22 (6), pp. 745-764. DOI: 10.1177/0963662511434894.

Dickinson, J. L., Shirk, J., Bonter, D., Bonney, R., Crain, R. L., Martin, J., Phillips, T. and Purcell, K. (2012). 'The current state of citizen science as a tool for ecological research and public engagement'. Frontiers in Ecology and the Environment 10 (6), pp. 291-297. DOI: 10.1890/110236.

Egger, A. E. (2007). 'Cultivating Citizen Scientists in the Undergraduate Science Classroom'. AGU Fall Meeting Abstracts 11. URL: http: //adsabs . harvard.edu/abs/2007AGUFMED11D . .01E.

Frantz, K., Carruth, L. and Goode, C. (November 2014). Collaborative Research for Novice Undergraduates. Poster presented at the AACU Transforming STEM Higher Education meeting, Atlanta, GA, U.S.A.

Freeman, S., Eddy, S. L., McDonough, M., Smith, M. K., Okoroafor, N., Jordt, H. and Wenderoth, M. P. (2014). 'Active learning increases student performance in science, engineering, and mathematics'. Proceedings of the National Academy of Sciences 111 (23), pp. 8410-8415. DOI: 10.1073/pnas.1319030111.

Gasper, B. J. and Gardner, S. M. (2013). 'Engaging Students in Authentic Microbiology Research in an Introductory Biology Laboratory Course is Correlated with Gains in Student Understanding of the Nature of Authentic Research and Critical Thinking'. Journal of Microbiology \& Biology Education 14 (1), pp. 25-34. DOI: 10.1128/jmbe.v14i1.460.

Hamilton, L. (2011). Case studies in educational research. British Educational Research Association on-line resource. URL: https://www. bera.ac.uk/researchers-res ources/publications/case-studies-in-educational-research.

Haywood, B. K. and Besley, J. C. (2014). ‘Education, outreach, and inclusive engagement: Towards integrated indicators of successful program outcomes in participatory science'. Public Understanding of Science 23 (1), pp. 92-106. DOI: 10.1177/0963662513494560.

Jacob, N. P. (2012). 'Investigating Arabia Mountain: A Molecular Approach'. Science 335 (6076), pp. 1588-1589. DOI: 10.1126/science. 1213692.

Johnson, R. B. and Onwuegbuzie, A. J. (2004). 'Mixed Methods Research: A Research Paradigm Whose Time Has Come'. Educational Researcher 33 (7), pp. 14-26. DOI: 10.3102/0013189X033007014.

Jordan, R. C., Gray, S. A., Howe, D. V., Brooks, W. R. and Ehrenfeld, J. G. (2011). 'Knowledge gain and behavioral change in citizen-science programs'. Conservation Biology: The Journal of the Society for Conservation Biology 25 (6), pp. 1148-1154. DOI: 10.1111/j.1523-1739.2011.01745.x.

Lucky, A., Savage, A. M., Nichols, L. M., Castracani, C., Shell, L., Grasso, D. A., Mori, A. and Dunn, R. R. (2014). 'Ecologists, educators, and writers collaborate with the public to assess backyard diversity in The School of Ants Project'. Ecosphere 5 (7), art78. DOI: 10.1890/ES13-00364.1. 
Mallow, J. V. (2006). 'Science anxiety: Research and action'. In: Handbook of College Science Teaching. Ed. by J. J. Mintzes and W. H. Leonard. Arlington, VA, U.S.A.: NSTA Press, pp. 3-14.

Miles, M. B. and Huberman, A. M. (1994). Qualitative Data Analysis: An Expanded Sourcebook. 2nd ed. SAGE Publications.

Miller, J. D. (2010). The conceptualization and measurement of civic scientific literacy for the twenty-first century. Ed. by J. Meinwald and J. G. Hildebrand. Cambridge, MA, U.S.A.: American Academy of Arts and Sciences. URL: http: //www . amacad.org/pdfs/slacweb.pdf.

Miller-Rushing, A., Primack, R. and Bonney, R. (2012). 'The history of public participation in ecological research'. Frontiers in Ecology and the Environment 10 (6), pp. 285-290. DOI: 10.1890/110278.

National Research Council (2005). America's Lab Report: Investigations in High School Science. URL: http://www . nap.edu/catalog/11311/americas-lab-report-inve stigations-in-high-school-science.

Nerbonne, J. F. and Nelson, K. C. (2004). 'Volunteer Macroinvertebrate Monitoring in the United States: Resource Mobilization and Comparative State Structures'. Society \& Natural Resources 17 (9), pp. 817-839. DOI: 10.1080/08941920490493837.

Pandya, R. E. (2012). 'A framework for engaging diverse communities in citizen science in the US'. Frontiers in Ecology and the Environment 10 (6), pp. 314-317. DOI: $10.1890 / 120007$.

Powell, N. L. and Harmon, B. B. (2014). 'Developing Scientists: A Multiyear Research Experience at a Two-Year College'. Journal of College Science Teaching 44 (2), pp. 11-17.

Price, C. A. and Lee, H.-S. (2013). 'Changes in participants' scientific attitudes and epistemological beliefs during an astronomical citizen science project'. Journal of Research in Science Teaching 50 (7). DOI: 10.1002/tea. 21090.

Rotman, D., Preece, J., Hammock, J., Procita, K., Hansen, D., Parr, C., Lewis, D. and Jacobs, D. (February 2012). 'Dynamic Changes in Motivation in Collaborative Citizen-science Projects'. In: Proceedings of the ACM 2012 Conference on Computer Supported Cooperative Work. New York, NY, USA: ACM, pp. 217-226. DOI: $10.1145 / 2145204.2145238$.

Sauermann, H. and Franzoni, C. (2015). 'Crowd science user contribution patterns and their implications'. Proceedings of the National Academy of Sciences 112 (3), pp. 679-684. DOI: 10.1073/pnas. 1408907112.

Shirk, J. L., Ballard, H. L., Wilderman, C. C., Phillips, T., Wiggins, A., Jordan, R., McCallie, E., Minarchek, M., Lewenstein, B. V., Krasny, M. E. and Bonney, R. (2012). 'Public participation in scientific research: a framework for deliberate design'. Ecology and Society 17 (2), p. 29.

Sibthorp, J., Paisley, K., Gookin, J. and Ward, P. (2007). 'Addressing response-shift bias: retrospective pretests in recreation research and evaluation'. Journal of Leisure Research 39 (2), pp. 295-315.

Steele, C. M. (1997). 'A threat in the air: How stereotypes shape intellectual identity and performance'. American Psychologist 52 (6), pp. 613-629. DOI: 10.1037/0003-066X.52.6.613.

Steininger, M. S., Hulcr, J., Šigut, M. and Lucky, A. (2015). 'Simple and Efficient Trap for Bark and Ambrosia Beetles (Coleoptera: Curculionidae) to Facilitate Invasive Species Monitoring and Citizen Involvement'. Journal of Economic Entomology 108 (3), pp. 1115-1123. DOI: 10.1093/jee/tov014. 
Varner, J. (2014). 'Scientific Outreach: Toward Effective Public Engagement with Biological Science'. BioScience 64 (4), pp. 333-340. DOI: 10.1093/biosci/biu021.

Weaver, G. C., Russell, C. B. and Wink, D. J. (2008). 'Inquiry-based and research-based laboratory pedagogies in undergraduate science'. Nature Chemical Biology 4 (10), pp. 577-580. DOI: 10.1038/nchembio1008-577.

Wiggins, A. and Crowston, K. (2011). 'From Conservation to Crowdsourcing: A Typology of Citizen Science'. In: 2011 44th Hawaii International Conference on System Sciences (HICSS). 2011 44th Hawaii International Conference on System Sciences (HICSS), pp. 1-10. DOI: 10.1109/HICSS . 2011.207.

Wright, S. L., Jenkins-Guarnieri, M. A. and Murdock, J. L. (2012). 'Career Development Among First-Year. College Students College Self-Efficacy, Student Persistence, and Academic Success'. Journal of Career Development 40 (4), pp. 292-310. DOI: 10.1177/0894845312455509.

Yaffe, K., Bender, C. and Sechrest, L. (2014). 'How Does Undergraduate Research Experience Impact Career Trajectories and Level of Career Satisfaction: A Comparative Survey'. Journal of College Science Teaching 44 (1), pp. 25-33. URL: http://digital.nsta.org/article/How+Does+Undergraduate+Research+Expe rience+Impact+Career+Trajectories+and+Level+of+Career+Satisfaction $\% 3$ A+A+Comparative+Survey/1783519/221015/article.html.

Yin, R. K. (2009). Case Study Research: Design and Methods. Thousand Oaks, CA, U.S.A.: SAGE.

Tyler Vitone is a graduate research assistant in the Entomology and Nematology Department at the University of Florida. His research investigates population genomics of introduced ant species using high-throughput sequencing of samples collected through School of Ants. In addition to working with citizen science as an educational tool, Tyler also teaches in undergraduate classes.

E-mail: tvitone@ufl.edu.

Kathryn A. Stofer is Research Assistant Professor of STEM Education and Outreach at the University of Florida. She holds a PhD in Science Education focused on Free-Choice Learning, MS in Science Journalism, and BS in Biology. Her research and Extension work on public engagement with agriscience investigates how non-professionals gather, access, and make use of current agriscience research and how agriscientists meaningfully share their work with broad audiences. E-mail: stofer@ufl.edu.

M. Sedonia Steininger is a PhD student at the University of Florida. Her master's thesis centered on the development and implantation of a large-scale monitoring program for bark and ambrosia beetles using the Backyard Bark Beetles citizen science project, which she also manages. Currently she is a PhD student working on delimitation of a cryptic ambrosia beetle species complex, Euwallacea fornicatus. E-mail: m.sedonia@ufl.edu. 
Jiri Hulcr is an assistant professor in the School of Forest Resources and Conservation at the University of Florida. His research investigates the relationships between insects, microbes and trees. His work in science communication centers around raising knowledge about the importance of bark and ambrosia beetles. E-mail: hulcr@ufl.edu.

Robert Dunn is an associate professor of biology and a writer in the Department of Applied Ecology at North Carolina State University. His research interests include public science, biodiversity, ecology, conservation, and climate change. He writes about science for public audiences, focusing on the stories of the scientists behind the science, who they are, what they do and how and why they did it.

E-mail: rrdunn@ncsu.edu.

Andrea Lucky is an assistant research scientist at the University of Florida. Her research areas include the evolution and biodiversity of ants and science education. Her science communication efforts include insect based citizen science projects, art-science collaborations and teaching entomology to diverse audiences.

E-mail: alucky@ufl.edu.

\section{How to cite}

Vitone, T., Stofer, K. A., Sedonia Steininger, M., Hulcr, J., Dunn, R. and Lucky, A. (2016). 'School of Ants goes to college: integrating citizen science into the general education classroom increases engagement with science'. JCOM 15(01), A03. 